\title{
Nanostructured luminescently labeled nucleic acids
}

\author{
Larry J. Kricka $^{1 *}$ | Paolo Fortina ${ }^{2,3}$ | Jason Y. Park ${ }^{4}$
}

${ }^{1}$ Department of Pathology and Laboratory Medicine, University of Pennsylvania Medical Center, 3400 Spruce Street, Philadelphia, Pennsylvania 19104, USA

${ }^{2}$ Department of Cancer Biology, Cancer Genomics Laboratory, Sidney Kimmel Cancer Center, Thomas Jefferson University Jefferson Medical College, Philadelphia, PA, USA

${ }^{3}$ Department of Molecular Medicine, Universita' La Sapienza, Rome, Italy

${ }^{4}$ Department of Pathology and the Eugene McDermott Center for Human Growth and Development, University of Texas Southwestern Medical Center, Dallas, Texas 75229, USA

\section{Correspondence}

Larry J. Kricka, Department of Pathology and Laboratory Medicine, University of Pennsylvania Medical Center, 3400 Spruce Street, Philadelphia, Pennsylvania 19104, USA. Email: kricka@mail.med.upenn.edu

\begin{abstract}
Important and emerging trends at the interface of luminescence, nucleic acids and nanotechnology are: (i) the conventional luminescence labeling of nucleic acid nanostructures (e.g. DNA tetrahedron); (ii) the labeling of bulk nucleic acids (e.g. single-stranded DNA, double-stranded DNA) with nanostructured luminescent labels (e.g. copper nanoclusters); and (iii) the labeling of nucleic acid nanostructures (e.g. origami DNA) with nanostructured luminescent labels (e.g. silver nanoclusters). This review surveys recent advances in these three different approaches to the generation of nanostructured luminescently labeled nucleic acids, and includes both direct and indirect labeling methods.
\end{abstract}

\section{KEYWORDS}

nucleic acid labeling, chemiluminescence, photoluminescence, electrochemiluminescence, nanostructures

\section{1 | INTRODUCTION}

Nucleic acids are arguably the singly most important class of molecules based on their central role in life. Rendering nucleic acids luminescent via direct or indirect labeling has facilitated the sensitive detection of this class of molecule. Directly and indirectly, luminescently labeled DNA and RNA underlie many important clinical assays.

In recent years, nanotechnology has begun to have an impact on many aspects of the analytical sciences. ${ }^{[1-3]}$ The convergence of nucleic acid and luminescence research with nanoscale science is an emerging trend. Luminescent labels such as chemiluminescent compounds or fluorophores have been used to label nucleic acids for several decades (Figure 1, overlap A). What has emerged in the past decade is the manipulation and modification of nucleic acids at the nanoscale (e.g., DNA tetrahedron) (Figure 1, overlap B). Similarly, labels and optical properties of labels can be modified and studied at the nanoscale level (e.g. silver nanoclusters) (Figure 1, overlap C). Finally, there are emerging applications of combining nanoscale properties of both nucleic acids and luminescent labels within the same system (Figure 1, overlap D).

This review surveys recent advances in the luminescent labeling of nucleic acids in which one or both of the components of the luminescent label-nucleic acid conjugate is nanosized or nanostructured. The more conventional luminescence labeling of nucleic acids (e.g. fluorescein labeling of single-stranded DNA) is represented by the overlapping regions $A$ in Figure 1, and this type of labeling has a long history and has been extensively reviewed previously. ${ }^{[4,5]}$

Work in these three areas at the intersection of nanotechnology, nucleic acids and labels has been motivated by the development of more sensitive labeling techniques, more efficient light absorption and energy transfer processes, aggregation-induced emission, 'turn-on' probes and programmed geometries for luminescent labels.

\section{I NUCLEIC ACIDS AND NUCLEIC ACID NANOSTRUCTURES}

The building blocks of the well known deoxyribonucleic acid (DNA) and ribonucleic acid (RNA) molecules are the adenine (A), guanine $(G)$, cytosine (C) and thymine (T) bases, with the thymine base being replaced by uracil $(U)$ in RNA. The diversity of the building blocks for DNA and RNA includes the so-called 'rare' or 'minor variant' or 'modified' bases that have been characterized (e.g., 5-hydroxymethyluracil, 5-dihydroxypentyluracil). ${ }^{[6-8]}$ In vivo, DNA methylation of cytosine or guanine nucleotides provides two other types of bases (methylcytosine and methylguanosine). Another level of nucleic acid diversity has been achieved by replacing natural with modified bases to create 'synthetic DNA' of different types. ${ }^{[9]}$ The current family of 


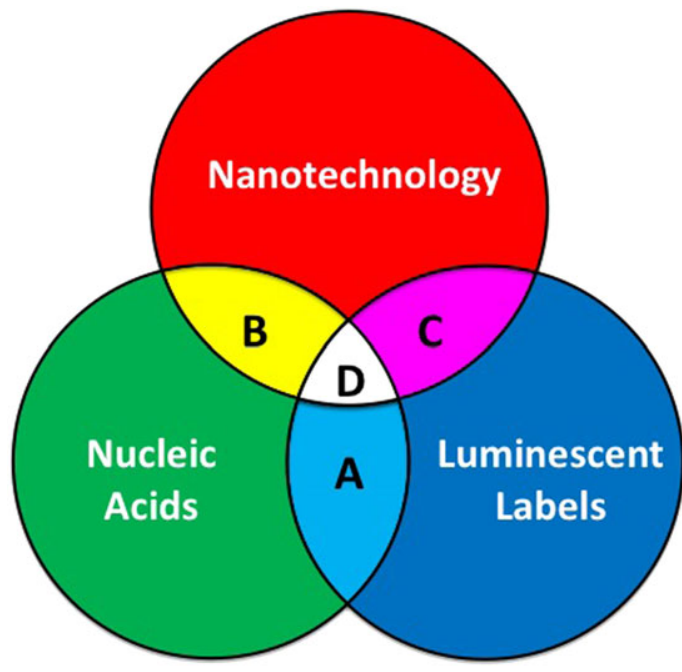

FIGURE 1 Intersecting research domains. Nucleic acid and luminescence research have converged with nanoscale science. Luminescent labels such as chemiluminescent compounds or fluorophores have been used to label nucleic acids for several decades (A). What has emerged in the past decade is the manipulation and modification of nucleic acids at the nanoscale level (B). Similarly, labels and optical properties of labels can be modified and studied at the nanoscale (C). Finally, there are emerging applications of combining nanoscale properties of nucleic acids and luminescent labels within the same system (D)

naturally occurring nucleic acids (DNA and RNA) includes mtDNA, mRNA, miRNA, siRNA, tRNA, tmRNA, rRNA, snRNA, snoRNA and gRNA. They possess a diverse range of functions including protein coding, translation, splicing and gene regulation.

Perhaps, more than any other polymer, nucleic acids display a considerable range of structural diversity. The iconic double-stranded DNA comprising two strands of DNA hydrogen-bonded by base pairing ( $\mathrm{A}: \mathrm{T}$ and $\mathrm{G}: \mathrm{C}$ ) is familiar to many, but nucleic acids can adopt other structures or be formed into different shapes. These diverse structures include single- and triple-stranded molecules, single- and double-stranded circular structures (e.g. mitochondrial DNA) and branched molecules. Internal hybridization can create hairpin loops in single-stranded molecules, and light can covalently link pyrimidine bases (e.g., thymine and cytosine) and create cross links between individual strands in the double-stranded DNA to produce four member carbon ring (cyclobutane) pyrimidine dimers. G-quadruplex secondary structures also can form in single-stranded DNA and RNA in vitro. These planar quartets are composed of stacked associations of Hoogsteen-bonded guanines. ${ }^{[10]}$

More sophisticated chemistry can create other shapes and structures including dendrimers, ${ }^{[11]}$ quadrilateral, ${ }^{[12]}$ cube, ${ }^{[12]}$ truncated octahedron $^{[12]}$ and square DNA. ${ }^{[13]}$ One approach to building DNA nanostructures has been to design 32-mers that act like nanoscopic Lego ${ }^{\circledR}$-like building blocks ('DNA bricks'). This approach has facilitated the creation of over 100 different three-dimensional shapes. ${ }^{[14,15]}$ Likewise, four oligonucleotides have been designed that spontaneously self-assemble to form a DNA tetrahedron with DNA double helices as the edges of the tetrahedral structure. ${ }^{[16]}$

Yet another route to different DNA-based structures is termed 'DNA origami' ${ }^{[17,18]}$ and this has led to a Mobius DNA strip, two interlocking DNA rings, ${ }^{[19]}$ tiles, and a wide range of other shaped objects (Figure 2). ${ }^{[20,21]}$ tRNA also has been used as a building block to fabricate an octahedron structure. ${ }^{[22]}$

DNA nanotechnology is a new field based on artificial nucleic acid structures for technological uses. Examples include, DNA machines (e.g. molecular tweezers, nanorobot) ${ }^{[23,24]}$ and DNA computing. ${ }^{[25,26]}$ A DNA computer described in 1994 achieved a 100 teraflop computing capacity ( $10^{14}$ operations per second); this was more powerful than the supercomputers available at that time. ${ }^{[25]}$ The computational power of nucleic acids has evolved over

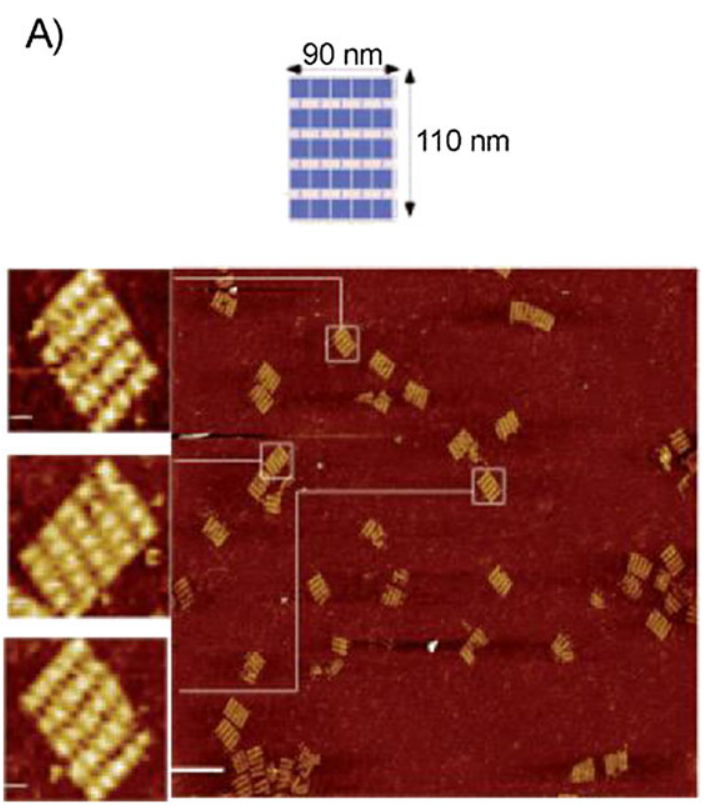

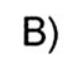
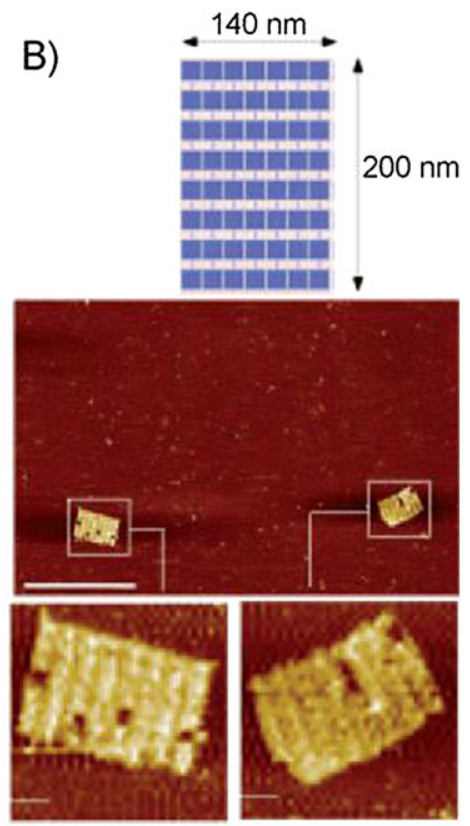

FIGURE 2 Nanostructured DNA origami. (a) Atomic force microscopy (AFM) images of the $5 \times 5$ structure. Scale bars in the insets are 20 nm. (b) AFM pictures for the $7 \times 8$ structures. Scale bars in the insets are $40 \mathrm{~nm}$. [The figure has been reproduced from Zhao et al. (2010) with permission from John Wiley and Sons] ${ }^{[20]}$ 
the past 20 years to include broader experimental use of 'nucleic acid-based logic gates'. [27]

Linking sequence with function and identifying and deciphering sequence motifs in DNA molecules has been a key focus for many decades since the original breakthrough in identifying three base sequences (triplet codons) as the instructions for amino acid sequence in protein synthesis. ${ }^{[28]}$ In the past, DNA sequence was often divided into DNA with identifiable function (e.g. genes) and the rest was termed 'junk DNA'. Increasingly, it is being recognized that junk DNA is a misnomer and that this DNA too has function. For example, the human ${ }^{[29]}$ and mouse ${ }^{[30]}$ Encyclopedia of DNA Elements (ENCODE) projects have demonstrated that intergenic noncoding DNA contains motifs for transcriptional regulation.

\section{I NANOSTRUCTURED LUMINESCENT LABELS}

There is a wide range of materials used to construct luminescent nanostructures and considerable diversity in the shapes and properties of the resulting nanostructures. ${ }^{[31-37]}$ Nanoparticles and nanoclusters represent one of the principal classes of nanostructures with luminescence properties, but particles with many other shapes have been fabricated including nanoprisms, nanorods and nanotubes.

The luminescence properties of a nanostructure are controlled by composition and also by the particle size and shape. Nanostructures useful as labels have been constructed from metals (gold, silver, copper) $^{[35]}$ (Figure 3a), semiconductor materials (e.g., CdSe, CdTe, $\mathrm{CdSeTe}$, ${ }^{[38]}$ silicon $^{[33]}$ and carbon (e.g. graphene, graphene oxide) (Figure $3 \mathrm{~b}){ }^{[39]}$ The size and shape of the structure, e.g., silver nanosphere vs silver nanoprism and the aspect ratio of a structure, ${ }^{[31]}$ can determine the luminescence emission wavelength. More complex nanostructured labels include solid core-shell structures ${ }^{[38]}$ and hollow spherical particles containing nanoparticle labels (quantum rattles). ${ }^{[40]}$

\section{1 | Luminescent nucleic acids}

A number of options exist for detecting nucleic acids. A nucleic acid may have a native luminescence (e.g. fluorescence), but usually this is too weak to be of routine use for sensitive detection. A nucleic acid can be rendered luminescent by physical methods such as intercalation of a fluorescent dye. Alternatively, a nucleic acid can be rendered luminescent by directly labeling the nucleic acid with an appropriate molecule that is inherently luminescent (e.g. a fluorophore) or with a label that can trigger a luminescent reaction (e.g. an enzyme label). Another strategy is to indirectly label the nucleic acid with a secondary label (e.g. biotin). The secondary label itself does not produce a signal, but it can be linked via an appropriate binder (e.g. streptavidin) to a luminescence reaction, by labeling the binder with a luminescent label or a label that can trigger a luminescence reaction. The following sections provide examples of these types of labeling strategies in the context of nanostructured labels and nanostructured nucleic acids.

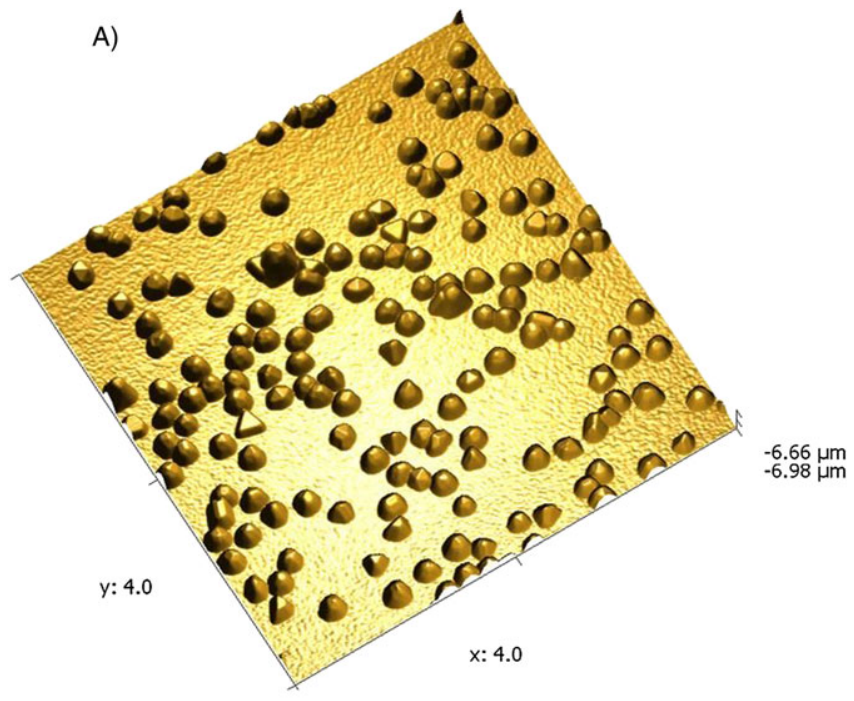

B)

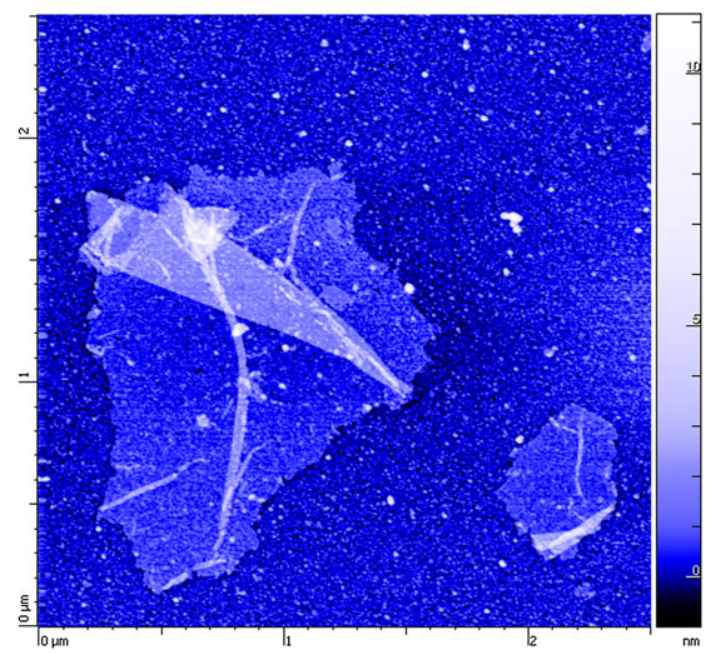

FIGURE 3 Nanostructured labels. (a) $150 \mathrm{~nm}$ gold nanoparticles $(4 \times 4$ micron 3D topography image of $150 \mathrm{~nm}$ Au nanoparticles immobilized on a Au-plated glass slide. (b) Single layer flakes of graphene oxide deposited on functionalized mica [2.5 $\times 2.5$ microns atomic force microscopy (AFM) topography image]. (Reproduced with permission from AIST-NT, Inc., Novato, California (http://www.aist-nt.com/)

\section{2 | Photoluminescent nucleic acids}

The diversity of photoluminescent (fluorescence, phosphorescence) labeling techniques for single-stranded and double-stranded nucleic acids has been reviewed previously. ${ }^{[4,5]}$ However, in recent years a significant body of literature on nanostructured photoluminescent labels for nucleic acids and photoluminescent labeled nucleic acid nanostructures has appeared, and this new direction in luminescent labeling of nucleic acids is reviewed in the following section.

\subsection{Nucleic acid nanostructures labeled with conventional labels}

Switch-on (turn-on) and switch-off (turn-off) assays based on fluorescent G-quadruplex nanostructures are an active area of research. The scope of assays based on the modulation of the fluorescence of 
G-quadruplex complexes includes assays for DNA, metal ions, enzymes, and biothiols. ${ }^{[41-49]}$

An example of the scheme for a switch-on T4 polynucleotide kinase activity assay is shown in Figure 4. Successive action of the T4 polynucleotide kinase and an exonuclease on a hairpin oligonucleotide results in potassium ion-mediated formation of a G-quadruplex structure from the digested hairpin. The G-quadruplex is rendered fluorescent (i.e. switched on) by binding to an iridium (III) complex. ${ }^{[41]}$

Switch-on assays have also been designed utilizing covalently labeled G-quadruplex structures that are formed by folding of a thrombin aptamer oligonucleotide labeled at the $5^{\prime}$-end with FAM and at the $3^{\prime}$ end with TAMRA. ${ }^{[45]}$ As shown in Figure 5, potassium ion-induced formation of the G-quadruplex structure facilitates fluorescence resonance energy transfer (FRET) due to the proximity of the terminal donor and acceptor fluorescent dyes, and the fluorescence signal was switched on.

Switch-off assay designs are also possible as illustrated by an assay for hepatitis viral DNA using tetrakis(dicyclohexylguanidino)-zincphthalocyanine (Zn-DIGP) as a G-quadruplex label. Binding of target DNA reduced the fluorescence from the $\mathrm{Zn}$-DIGP label complexed to the G-quadruplex structure. ${ }^{[46]}$

Fluorescent DNA tetrahedron nanostructures also have been prepared. For example, a DNA tetrahedron nanostructure was assembled with SYBR green I ${ }^{[50]}$ or YOYO- $1^{[51]}$ inserted into the structure to form fluorescent DNA. Covalent attachment of an acceptor dye, such as Cy3 facilitates energy transfer from the intercalated dyes (YOYO-1) and provides a route to multicolor fluorescence labeling. ${ }^{[51]}$

DNA origami nanostructures have been employed as a scaffold that allows the placement of a defined number of fluorophores at defined locations to produce so-called 'nanorulers'. These fluorescent DNA origami nanorulers can have arrangements of fluorescent marks of different color ranging from $6 \mathrm{~nm}$ to $400 \mathrm{~nm}$. The range of origami DNA structures includes six and 12 helix bundles, rectangles and nanopillars. ${ }^{[52]}$

FIGURE 4 G-quadruplex-based luminescence assay for the detection of T4 polynucleotide kinase (PNK) activity. A hairpin oligonucleotide with a 3'-G-quadruplex sequence (green) has a complementary sequence (blue) and a linker hairpin (red). T4 PNK phosphorylates the $5^{\prime}$ nucleotide $\left(\mathrm{PO}_{4}\right)$ allowing efficient degradation of the complementary sequence (blue) by lambda $(\lambda)$ exonuclease (yellow cartoon character). Lambda exonuclease does not degrade single-stranded DNA, so the remaining linker (red) and G-quadruplex sequences are intact; the resulting molecule folds into the G-quadruplex structure in the presence of potassium ions $(\mathrm{K}+)$. Interaction between the $\operatorname{Ir}(\mathrm{III})$ complex $1[\operatorname{Ir}(\mathrm{ptpy}) 2(\mathrm{dpp})$ where ptpy $=2$-(p-tolyl) pyridine; $d p p=2,9$ diphenyl-1,10-phenanthroline)] and the Gquadruplex results in enhanced luminescence. [The figure has been reproduced from $\mathrm{He}$ et al. (2014) with the permission of the Royal Society of Chemistry (http://dx.doi.org/ $10.1039 / \mathrm{c} 3 \operatorname{cc} 47444 \mathrm{e})^{[41]}$.]

\subsection{Nucleic acids labeled with nanostructured labels}

Nanotechnology also has played a part in photoluminescent labeling of nucleic acids. Double-stranded DNA can be metalized with copper nanoparticles (nanoclusters) by reducing bound copper ions with ascorbate in the presence of DNA. The DNA-Cu nanoparticle complexes fluoresce at around $\sim 600 \mathrm{~nm}$. The size of the nanoparticles and the fluorescence intensity is dependent on the number of base pairs in the double-stranded DNA. ${ }^{[53]}$ This labeling technique can be used to distinguish SNPs based on the influence of base type on the nanoparticle formation, ${ }^{[54]}$ and also used to assess kinase activity. ${ }^{[55]}$

In recent years, silver nanoclusters have found use as fluorescent labels for DNA with advantages of good photostability, high quantum yield and ease of synthesis. ${ }^{[56-58]}$ Silver ions bind to DNA and they can then be reduced to metallic silver by treatment with sodium borohydride to produce silver nanoclusters. Early work investigated the formation of silver nanoclusters with a short oligonucleotide (12-mer) (1-4 Ag/oligonucleotide; fluorescence peak at $642 \mathrm{~nm}$ with $580 \mathrm{~nm}$ excitation). ${ }^{[56]}$ Subsequently, studies with a dC12 oligonucleotide showed up to seven bound silver atoms in the red-emitting product. ${ }^{[59]}$ A DNA microarray has been used to screen 12-mers comprised of $A, T$ and $C$ bases; $G$ was not part of the sequence because of the propensity of this base for self-binding. This led to the identification of blue, green, yellow, red and near infra-red fluorescent 12-mer silver nanoclusters. ${ }^{[60]}$ Polycytosine loops have been incorporated in some probes as templates for formation of silver nanoclusters. ${ }^{[61]}$

Detection of microRNA has been accomplished based on a redemitting 12-mer silver nanocluster as a label. When the DNA sequence complementary to miR160 microRNA, previously covalently linked to the 12-mer, was treated with silver nitrate and sodium borohydride it produced silver nanoclusters on the 12-mer and to a lesser extent on the DNA probe. The fluorescence of this silver nanocluster-12-mer

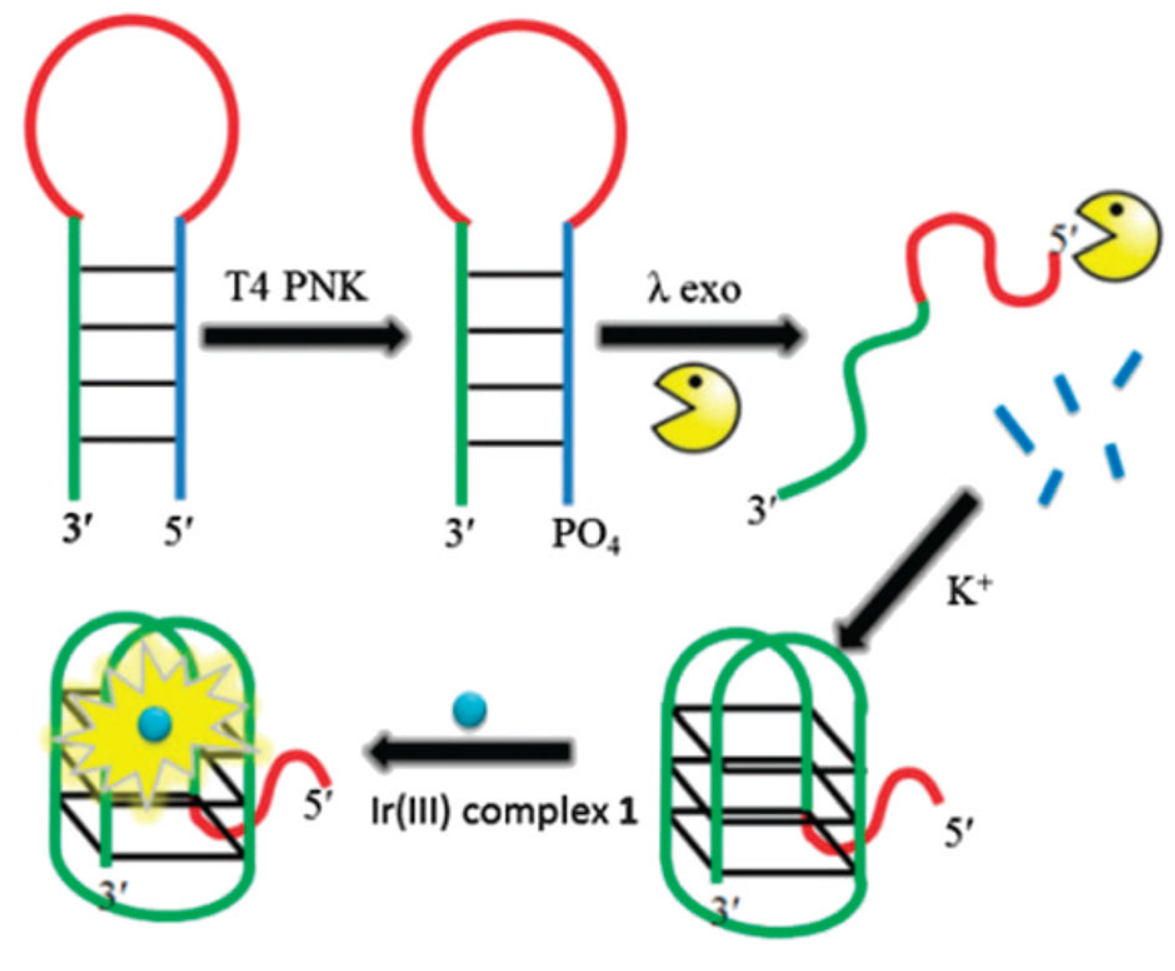


a
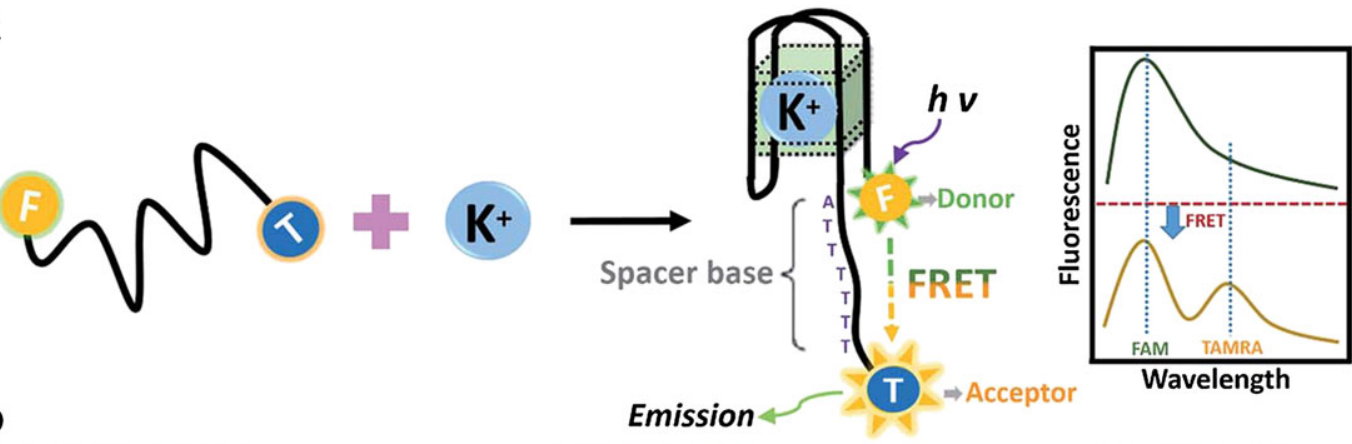

Wavelength

b
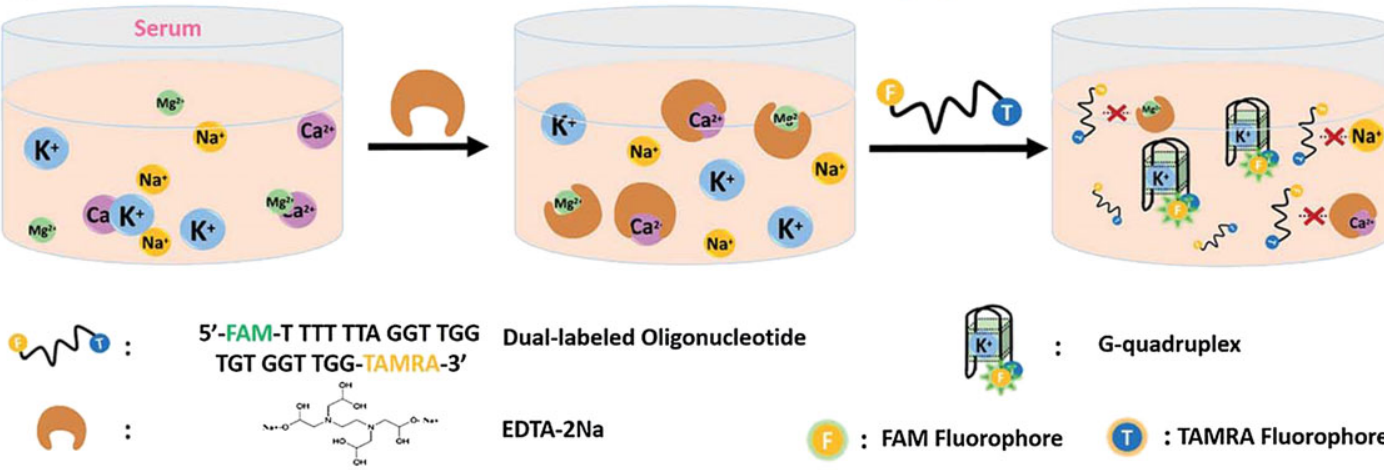

ual-labeled Oligonucleotide

EDTA-2Na

: FAM Fluorophore

G-quadruplex

: TAMRA Fluorophore

FIGURE 5 G-quadruplex FRET assay for the detection of potassium ions (K+). A FRET probe with FAM (F) and TAMRA (T) fluorescent dyes form a $\mathrm{G}$-quadruplex in the presence of $\mathrm{K}+(\mathrm{a})$. The formation of the G-quadruplex results in energy transfer from the FAM (fluorescein) donor to the TAMRA (tetramethylrhodamine) acceptor and results in longer wavelength emission. Calcium $\left(\mathrm{Ca}^{2+}\right)$ and magnesium $\left(\mathrm{Mg}^{2+}\right)$ may cause assay interference and are therefore chelated from the serum sample (b). [The figure has been reproduced from Zhang et al. (2016) with the permission of the Royal Society of Chemistry (http://dx.doi.org/10.1039/c6ra04046b) ${ }^{[45]}$.]

DNA probe diminished significantly when bound to the complementary RNA in miR160 (Scheme 1). ${ }^{[62]}$

One type of fluorescent silver nanocluster DNA probe has been termed a 'chameleon NanoCluster Beacon'. ${ }^{[63]}$ Binding of the labeled G-rich probes at locations adjacent to a SNP in the wild-type and mutant targets resulted in different coloured emissions from the labeled probe (a 60-70 nm shift in emission wavelength). The silver nanocluster DNA probe itself did not produce a signal unless bound to the target.

Indirect labeling with silver nanoclusters also is viable, as exemplified by a fluorescent avidin-24-mer cytosine-silver nanocluster (emission at $634 \mathrm{~nm}$, fluorescence lifetime $2.86 \mathrm{~ns}$ ) used for cell-surface labeling. ${ }^{[64]}$

A nanoflare comprises a gold nanoparticle (e.g. $13 \mathrm{~nm}$ diameter) densely coated with capture probe to which is hybridized a displaceable Cy5-labeled reporter probe. ${ }^{[65,66]}$ In this so-called 'spherical nucleic acid', the fluorescence signal of the Cy5 dye is quenched by the gold nanoparticle. Displacement of the reporter probes by target nucleic acid abolishes the quenching and a bright 'flare' of fluorescence is generated (Scheme 2).

Carbon nanotubes can quench fluorescence and this property has been exploited in a non-separation type of assay for DNA (Scheme 3). The fluorescence signal from a fluorescent hairpin DNA probe is quenched on binding to a single-walled carbon nanotube. Competitive binding of the labeled probe with target DNA and the nanotube leads to a fluorescence signal that is directly proportional to the concentration of target DNA present. In this context the carbon nanotube acts both as a quencher label, and as a nanoscaffold for the DNA probe. ${ }^{[67]}$

Other carbon nanostructures are useful as labels for nucleic acids, notably carbon dots (C-dots or carbonic nanodots). These are carboncontaining nanoparticles that can quench fluorescence or they can be made fluorescent by modification with various coating materials (e.g. polyethylene glycol) or dopants (e.g. ZnO or ZnS). ${ }^{[39,68]}$ Graphene quantum dots are yet another type of carbon-based nanoparticle that can be engineered to emit light from the blue-green to the orangered region depending on size and structure. ${ }^{[69,70]}$

The quenching property of a carbon nanoparticles and water soluble graphene oxide (one atom thick carbon sheets) have been exploited in an assay in which a fluorescent probe and target are hybridized and then graphene oxide added to the mixture. Any unbound fluorophore labeled probe is adsorbed to the surface of the nanoparticle and the fluorescence is quenched. An alternative strategy first binds the fluorescent probe to the graphene oxide and then exposes the immobilized probe to target, which hybridizes and releases the probe from the graphene oxide and restores fluorescence signal. In both assay strategies, the observed fluorescence is directly proportional to the concentration of the target DNA (detection limit 100 pM for a DNA oligonucleotide). ${ }^{[39,71,72]}$ An alternative energy transfer strategy

$$
\text { Probe-12-mer }(\mathrm{Ag})_{\mathrm{n}}+\operatorname{miR} 160 \rightarrow \text { miRNA:Probe-12-mer }(\mathrm{Ag})_{\mathrm{n}}
$$


AuNP-(probe:PROBE-F)n + Target $\rightarrow$ AuNP-(probe:Target)n + n PROBE-F

(quenched)

(fluorescent)
(AuNP = gold
nanoparticle;
probe $=$ capture
probe; $\quad$ PROBE-F = fluorescently labeled reporter probe.)

SCHEME 2

\author{
Quencher:Probe-F + Target $\rightarrow$ Quencher + Target:Probe-F \\ (quenched) \\ (fluorescent)
}

(Quencher $=$ carbon nanotube, graphene oxide, $\mathrm{C}$-dot; F = fluorophore)

SCHEME 3

exploits the fluorescence properties of graphene oxide (emission maximum $546 \mathrm{~nm}$ ). A DNA probe was covalently immobilized on graphene oxide (one atom thick sheets, lateral dimensions $500 \mathrm{~nm}$ to $1 \mu \mathrm{m}$ ) arrayed as spots on a glass slide. Binding of gold nanoparticle-labeled target led to quenching of the fluorescence signal from the graphene oxide spot (Scheme 4). ${ }^{\text {[7] }}$

Quantum dots have been investigated extensively as fluorescent labels for nucleic acids. The scope of quantum dot labels includes quantum dots functionalized with a platinum chelate to affect fluorescent labeling via guanine residues ${ }^{[74]}$, and green or red fluorescent liposome-CdSe quantum dot complexes as labels for oligonucleotides. ${ }^{[75]}$

Mn-doped ZnS quantum dots are phosphorescent, and this emission is quenched when a Mn-doped ZnS quantum dot-labeled DNA probe is bound to a carbon nanotube. Hybridization with target releases the probe from the nanotube surface and the phosphorescence of the label is restored. ${ }^{[76]}$

Another type of assay strategy involves modulation of a luminescent signal when a nucleic acid binds to a luminescent nanostructure. For example, nanoparticle composites comprising an organic dye (Morin) and $\mathrm{SiO}_{2}$ nanoparticles ( $50 \mathrm{~nm}$ diameter) exhibit room temperature phosphorescence when bound to a polyamide membrane. Binding of DNA enhances the phosphorescence emission and this forms the basis of detecting DNA (limit of detection $1.5 \mathrm{pg} / \mathrm{mL}$ ). ${ }^{[77]}$ Likewise, nanohybrids formed by interaction of polyhedral oligomeric octa(3aminopropyl)octasilsequioxane and $\mathrm{Mn}$-doped $\mathrm{ZnS}$ nanoparticles can act as sensors for DNA. Binding of DNA quenches the room temperature phosphorescence of the complexes. ${ }^{[78]}$
Up-converting phosphor nanoparticles are a type of nanoparticle that convert long wave incident excitation light into shorter wavelength emissions (anti-Stokes emission). Up-converting green-emitting $\mathrm{Y}_{2} \mathrm{O}_{2} \mathrm{~S}$ : $\mathrm{Yb}$,Er phosphor nanoparticles (400 $\mathrm{nm}$ diameter) have been used to detect DNA on microarrays, ${ }^{[79]}$ and up-converting ytterbium-erbium nanoparticles have been used as labels in lateral-flow assays to screen for the presence of human papillomavirus type 16. ${ }^{[80]}$ Another up-converting phosphor used for DNA detection is the nanoparticulate $\mathrm{Yb}^{3+} / \mathrm{Er}^{3+}$ ion-pair doped hexagonal phase $\mathrm{NaYF}_{4} \cdot{ }^{[81]}$

\section{5 | Nucleic acid nanostructures labeled with nanostructured labels}

A DNA nanowire labeled with a silver nanocluster provides an example of a nanostructured label for a DNA nanostructure. ${ }^{[82]}$ Micrometrelong red- or yellow-emitting silver nanocluster - DNA nanowires, containing C-rich hairpin templates for silver nanocluster formation were synthesized by either a hybridization-polymerization process or a hybridization chain reaction. Another example is provided by rectangular DNA origami-containing biotinylated strands that were rendered fluorescent via binding to a streptavidin-coated CdSe-ZnS core-shell QDs. ${ }^{[83]}$ Also, guanine-rich DNA in the form of a G-quadruplex also can be labeled with silver nanoclusters, and this type of probe has found application in bioimaging. ${ }^{\left[{ }^{84]}\right.}$ Finally, double labeling is possible as exemplified by the labeling of a rectangular DNA origami template with single-stranded DNA-coated gold nanoparticles on one side and

$$
\begin{aligned}
& \text { GO-Probe }+ \text { Target-AuNP } \rightarrow \text { GO-Probe:Target-AuNP } \\
& \text { (fluorescent) } \\
& \text { (quenched) }
\end{aligned}
$$$$
(\mathrm{GO}=\text { graphene oxide; } \mathrm{AuNP}=\text { gold nanoparticle })
$$ 
with quantum dots on the opposite side of the origami structure (Figure 6). ${ }^{[85]}$

\section{4 | CHEMILUMINESCENT NUCLEIC ACIDS}

Chemiluminescence has become an established detection technology for nucleic acids based on direct chemiluminescent labels (e.g. acridinium ester), or chemiluminescent detection of enzyme labels, such as alkaline phosphatase using chemiluminescent 1,2-dioxetane substrates. ${ }^{[4]}$

The nanostructured labels for nucleic acids described to date are mostly indirect labels that are detected via catalysis of a chemiluminescent reaction, as described below.

\section{1 | Nucleic acid nanostructures labeled with conventional labels}

A biotinylated DNA probe photochemically cross-linked to a nylon 6:6 nanotube-nanorod mixture provides an example of a composite nucleic acid nanostructure. ${ }^{[86]}$ This structure was rendered chemiluminescent via binding to streptavidin-alkaline phosphatase and subsequent detection of the alkaline phosphatase label using a chemiluminescent dioxetane substrate.

\section{2 | Nucleic acids labeled with nanostructured labels}

Nanoparticle labels represent the most extensively investigated type of nanostructured label for chemiluminescent detection of nucleic acids. ${ }^{[87]}$ Gold nanoparticle-labeled DNA probes can be detected via their catalytic activity on the chemiluminescent luminol reaction. Studies have shown that irregularly shaped Au nanoparticle labels are more effective catalysts than spherical nanoparticle labels. ${ }^{[88]}$

Silver, ${ }^{[89]}$ magnetic iron ${ }^{[90]}$ and Co nanoparticles ${ }^{[91]}$ also are used as labels for DNA probes. Prior to detection, the NP label is treated with nitric acid to release $\mathrm{Ag}^{+}, \mathrm{Fe}^{3+}$ and $\mathrm{Co}^{2+}$, metal ions, respectively. The released metal ions are then detected via their catalytic activity in the chemiluminescent luminol reaction.

Fluorescent carbon nanodots in the presence of oxidants (e.g., $\mathrm{KMnO}_{4}$ ) produce a chemiluminescent emission (peaks at 500 and $650 \mathrm{~nm}$ ). ${ }^{[92]}$ This type of nanoparticle has been used as a label in combination with nanoporous gold as an amplifier in a low-cost paperbased assay for DNA with a detection limit of $8.5610^{-19} \mathrm{M} .^{[93]}$

\section{5 | ELECTROCHEMILUMINESCENT NUCLEIC ACIDS}

Electrochemiluminescence-active substances include transition metal complexes (e.g., tris-bipyridyl ruthenium (TBR) chelates), various organic molecules (e.g., luminol) and nanomaterials (e.g., quantum dots). Both TBR-nanoparticle composites and quantum dot label have found use for electrochemiluminescent labeling of nucleic acids.

\section{1 | Nucleic acids labeled with nanostructured labels}

TBR labels also have been used in combination with gold nanoparticles in a biobarcode-based assay scheme (detection limit $100 \mathrm{fM}$ ). ${ }^{[94]} \mathrm{A}$ mixture of a 27-mer oligonucleotide probe and cysteamine biobarcodes were attached to gold nanoparticles and then TBR labels were covalently attached to the free amino group of cysteamine to form the biobarcode reagent.

The electrochemiluminescent properties of a TBR label can be modulated by the proximity of a quencher such as ferrocene. A molecular beacon-type oligonucleotide probe was synthesized to have a ferrocene label at one end and the other end was bound to a gold nanoparticle-TBR composite. The close proximity of the labels leads to quenching of the TBR electrochemiluminescence by the ferrocene label. Binding of target to the labeled probe opens the hairpin and the electrochemiluminescent property of the TBR label is restored. ${ }^{[95]}$

Other electrochemiluminescent labels include different types of quantum dots (e.g., CdS, CdTe ${ }^{[96]}$ and metal nanoparticle composites [e.g. PdCu@carbon, ${ }^{[97]}$ luminol-Pt, ${ }^{[98]} \mathrm{CaCO}_{3}$-carboxymethyl chitosan microspheres@Ag nanoparticles, ${ }^{[99]}$ CdS QD-dendrimer nanocomposites ${ }^{[100]}$. Quantum dot labeling also can be achieved via an indirect labeling strategy involving biotinylated DNA and avidin-modified quantum dots. ${ }^{[101]}$

\subsection{Clinical in vitro nanostructured luminescent assays}

There are many examples of clinical laboratory assays that incorporate aspects of nanotechnology ${ }^{[102-104]}$ but there are no commercialized assays which specifically utilize nanostructured luminescently labeled nucleic acids such as those described in this survey.

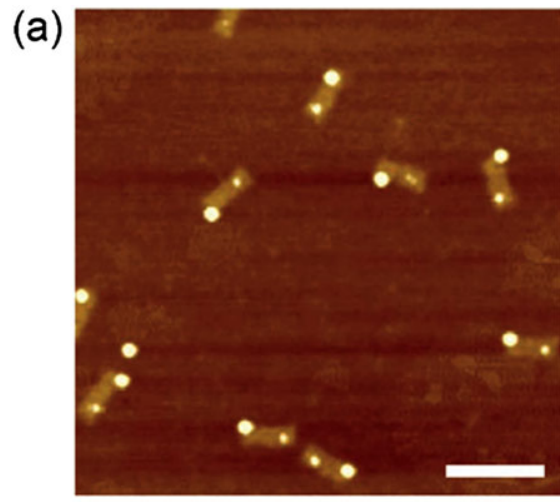

(b)
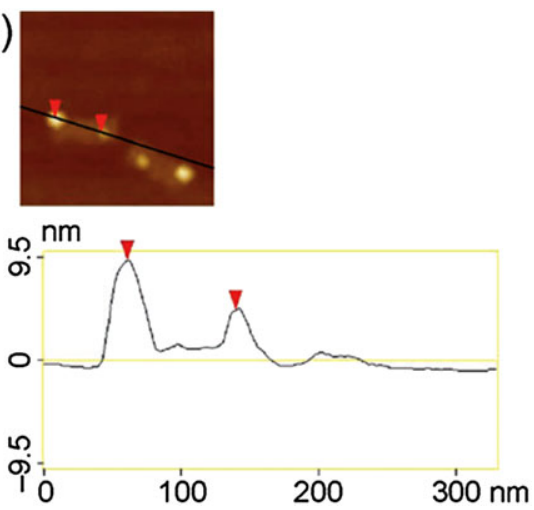

FIGURE 6 Nucleic acid nanostructures labeled with nanostructured labels. (a) Atomic force microscopy (AFM) image of the assembly of streptavidin-coated CdSe quantum dots (core diameter $\sim 5 \mathrm{~nm}$ ) and single-stranded DNA-coated gold nanoparticles (10 nm diameter) on opposite sides of a rectangular DNA origami template (scale bar is $200 \mathrm{~nm}$ ). (b) Cross-section profile analysis showing the height difference between the streptavidincoated quantum dots and the single-stranded DNA-coated gold nanoparticles. [This figure has been reproduced from Wang et al 2012 with permission from John Wiley and Sons. $]^{[85]}$ 
Traditional nucleic acid testing is the bulk combination of nucleic acids and luminescent labels that include intercalating dyes (ethidium bromide, SYBR green) and conjugated fluorescent molecules (e.g. fluorescein). These traditional assay formats are used in agarose gel electrophoresis, capillary electrophoresis, real-time PCR, Sanger sequencing and massively parallel, next generation sequencing. ${ }^{[4]}$ Although the principles of these assays rely on intermolecular interactions, the combination of assays components occur at the macroscale without designed/engineered features for either the label of the nucleic acid at the nanoscale.

In recent years, there has been an emergence of nanolabels. A good example is the use of colloidal gold in immunoassays and in nucleic acid assays in which the gold nanosized-gold particles are detected via light scattering (e.g. the Verigene system). ${ }^{[105]}$ Assay formats using unique nucleic acid nanostructures with inherent luminescent properties or nucleic acid nanostructures conjugated to luminescent molecules have not yet been commercialized. Although manipulating nucleic acids at the nanoscale yields fascinating structures with unique biophysical properties, the rate of adoption and commercialization into clinical testing will be governed by innovation that provides compelling advantages over existing technologies. Continued unmet needs for clinical diagnostic assays include ultra-high sensitivity analyte detection (i.e. single-molecule detection), decreased interference or cross-reactivity with other biological molecules, and minimally invasive or non-invasive analyte detection. Perhaps, luminescent nucleic acid nanostructures will provide advantages in these areas of need within the clinical laboratory. Finally, such tests must be cost effective, sensitive and require minimal effort and time to perform and analyze.

\section{6 | CONCLUSION}

Nanotechnology is providing new types of nanostructured luminescent labels and assay strategies for detecting nucleic acids. Most are at an early stage of development, but the beneficial properties of nanolabels, such as stability, brightness and biocompatibility are fueling continued research and development. It remains to be seen if nanostructured labels will displace conventional luminescent nucleic acid labels. Likewise, the role of nucleic acid nanostructures in analysis is unclear. This is also a highly active area of research that includes applications in photonics and therapeutics ${ }^{[106]}$, and developments in these areas may well spark future applications for nucleic acid nanostructures in routine clinical diagnostics.

\section{ABBREVIATIONS USED}

$\begin{array}{ll}\text { A } & \text { adenine } \\ \text { AFM } & \text { atomic force microscopy } \\ \text { C } & \text { cytosine } \\ \text { G } & \text { guanine } \\ \text { gRNA } & \text { guide RNA } \\ \text { mRNA } & \text { messenger RNA } \\ \text { miRNA } & \text { micro RNA } \\ \text { mtDNA } & \text { mitochondrial DNA }\end{array}$

rRNA ribosomal RNA

SiRNA small interfering RNA

SNP single-nucleotide polymorphism

snRNA small nuclear RNA

snoRNA small nucleolar RNA

$T$ thymine

TBR tris-bipyridyl ruthenium

tRNA transfer RNA

tmRNA transfer-messenger RNA

\section{REFERENCES}

[1] P. Fortina, J. Wang, S. Surrey, J. Y. Park, L. J. Kricka, In Integrated Biochips for DNA Analysis (Eds: R. H. Liu, A. P. Lee), Springer, New York, USA 2007, p. 187.

[2] P. Fortina, L. J. Kricka, S. P. Surrey, P. Grodzinski, Trends Biotechnol. 2005, 23, 168.

[3] D. Branton, D. W. Deamer, A. Marziali, H. Bayley, S. A. Benner, T. Butler, M. Di Ventra, S. Garaj, A. Hibbs, X. Huang, S. B. Jovanovich, P. S. Krstic, S. Lindsay, X. S. Ling, C. H. Mastrangelo, A. Meller, J. S. Oliver, Y. V. Pershin, J. M. Ramsey, R. Riehn, G. V. Soni, V. Tabard-Cossa, M. Wanunu, M. Wiggin, J. A. Schloss, Nat. Biotechnol. 2008, 26, 1146.

[4] L. J. Kricka, Ann. Clin. Biochem. 2002, 39, 114.

[5] L. J. Kricka, P. Fortina, Clin. Chem. 2009, 55, 670.

[6] B. F. Vanyushin, S. G. Tkacheva, A. N. Belozersky, Nature 2015, 225, 948.

[7] J. H. Gommers-Ampt, P. Borst, FASEB J. 1995, 9, 1034.

[8] B. E. Maden, Prog. Nucleic Acid Res. Mol. Biol. 1990, 39, 241.

[9] R. Kwok, Nature 2012, 491, 516.

[10] Y. Wu, R. M. Brosh Jr, FEBS J. 2010, 277, 3470.

[11] M. S. Shchepinov, K. U. Mir, J. K. Elder, M. D. Frank-Kamenetskii, E. M. Southern, Nucleic Acids Res. 1999, 27, 3035.

[12] N. C. Seeman, Annu. Rev. Biophys. Biomol. Struct. 1998, 27, 225.

[13] P. W. K. Rothemund, Nature 2006, 440, 297.

[14] Y. Ke, L. L. Ong, W. M. Shih, P. Yin, Science 2012, 338,1177.

[15] A. Casini, M. Storch, G. S. Baldwin, T. Ellis, Nat. Rev. Mol. Cell. Biol. 2014, 16, 568

[16] R. P. Goodman, R. M. Berry, A. J. Turberfield, Chem. Commun. 2004, 12, 1372.

[17] J. Nangreave, D. Han, Y. Liu, H. Yan, Curr. Opin. Chem. Biol. 2010, 14, 608.

[18] K. E. Dunn, F. Dannenberg, T. E. Ouldridge, M. K. Kwiatkowska, A. J. Tuberfiled, J. Bath, Nature 2015, 525, 82.

[19] D. Han, S. Pal, Y. Liu, H. Yan, Nat. Nanotechnol. 2010, 5,712.

[20] Z. Zhao, H. Yan, Y. Liu, Angew. Chem. Intl. Ed. Engl. 2010, 49, 1414.

[21] E. Stahl, T. G. Martin, F. Praetorius, H. Dietz, Angew. Chem. Intl. Ed. 2014, 53, 12735.

[22] I. Severcan, Nature Chem. 2010, 2, 772.

[23] B. Yurke, A. J. Turberfield, A. P. Mills, F. C. Simmel, J. L. Neumann, Nature 2000, 406, 605

[24] T. Gerling, K. F. Wagenbauer, A. M. Neuner, H. Dietz, Science 2015, 27, 1446.

[25] L. M. Adleman, Science 1994, 266, 1021.

[26] J. Parker, EMBO J. 2003, 4, 7.

[27] C. Wu, S. Wan, W. Hou, L. Zhang, J. Xu, C. Cui, Y. Wang, J. Hu, W. Tan, Chem. Commun. 2015, 51, 3723.

[28] M. W. Nirenberg, H. J. Matthaei, Proc. Natl. Acad. Sci. USA 1961, 47, 1588.

[29] ENCODE Project Consortium, PLoS Biol. 2011, 9, e1001046.

[30] Mouse ENCODE Consortium, Genome Biol. 2012, 13, 418. 
[31] S. Horikoshi, N. Serpone in Microwaves in Nanoparticle Synthesis: Fundamentals and Applications (Eds: S. Horikoshi, N. Serpone), Wiley-VCH, Weinheim, Germany 2013, Ch.1.

[32] C. Knoblauch, M. Griep, C. Friedrich, Sensors 2014, 14, 19731.

[33] X. He, N. Ma, Colloids Surfaces B: Biointerfaces 2014, 124, 118.

[34] J. M. Obliosca, C. Liu, H. C. Yeh, Nanoscale 2013, 5, 8443.

[35] J. Zheng, P. R. Nicovich, R. M. Dickson, Annu. Rev. Phys. Chem. 2007, $58,409$.

[36] W. Deng, E. M. Goldys, Analyst 2014, 139, 5321.

[37] A. Heuer-Jungemann, P. K. Harimech, T. Brown, A. G. Kanaras, Nanoscale 2013, 5, 9503.

[38] D. Vasudevan, R. R. Gaddam, A. Trinchi, I. Cole, J. Alloys Compds $2015,636,395$

[39] C. Ding, A. Zhu, Y. Tian, Acc. Chem. Res. 2014, 47, 20.

[40] M. Hembury, C. Chiappini, S. Bertazzo, T. L. Kalber, G. L. Drisko, O. Ogunlade, S. Walker-Samuel, K. S. Krishna, C. Jumeaux, P. Beard, C. S. Kumar, A. E. Porter, M. F. Lythgoe, C. Boissière, C. Sanchez, M. M. Stevens, Proc. Natl. Acad. Sci. USA 2015, 12, 1959.

[41] H.-Z. He, K.-H. Leung, W. Wang, D. S.-H. Chan, C.-H. Leung, D.-L. Ma, Chem. Commun. 2014, 50, 5313.

[42] H.-Z. He, D. S.-H. Chan, C.-H. Leung, D.-L. Ma, Nucleic Acids Res. 2013, 41, 4345

[43] D. L. Ma, H.-Z. He, K.-H. Leung, H.-J. Zhong, D. S.-H. Chan, C.-H. Leung, Chem. Soc. Rev. 2013, 42, 3427.

[44] B. R. Vummidi, J. Alzeer, N. W. Luedtke, Chembiochem. 2013, 14, 540.

[45] S. Zhang, R. Zhang, B. Ma, J. Qiu, L. Ji, Y. Sang, W. Liu, H. Liu, RSC Adv. 2016, 6, 41999.

[46] J. Ren, H. Qin, J. Wang, N. W. Luedtke, E. Wang, J. Wang, Anal. Bioanal. Chem. 2011, 399, 2763.

[47] D. Ding, K. Li, B. Z. Tang, Acc. Chem. Res. 2013, 46, 2441.

[48] Q. Shen, L. Zhou, Y. Yuan, Y. Huang, B. Xiang, C. Chen, Z. Nie, S. Yao, Biosens. Bioelectron. 2014, 55, 187.

[49] W. Yang, Y. Ruan, W. Wu, P. Chen, L. Xu, F. Fu, Anal. Bioanal. Chem. 2014, 406, 4535.

[50] Y. Ding, X. Liu, J. Zhu, L. Wang, W. Jang, Talanta 2014, 125, 393.

[51] H. Ozhalici-Unal, B. A. Armitage, ACS Nano. 2009, 3, 425.

[52] S. Beater, M. Raab, P. Tinnefeld, Methods Cell. Biol. 2014, 123, 449.

[53] A. Rotaru, S. Dutta, E. Jentzsch, K. Gothelf, A. Mokhir, Angew. Chem. Intl. Ed. Engl. 2010, 49, 5665.

[54] X. Jia, J. Li, L. Han, J. Ren, X. Yang, E. Wang, ACS Nano. 2012, 6, 3311.

[55] L. Zhang, J. Zhao, H. Zhang, J. Jiang, R. Yu, Biosens. Bioelectron. 2013 $44,6$.

[56] J. T. Petty, J. Zheng, N. V. Hud, R. M. Dickson, J. Am. Chem. Soc. 2004, 126, 5207

[57] J. Sharma, R. C. Rocha, M. L. Phipps, H. C. Yeh, K. A. Balatsky, D. M. Vu, A. P. Shreve, J. H. Werner, J. S. Martinez, Nanoscale 2012, 4, 4107.

[58] Z. Yuan, Y.-C. Chen, H.-W. Li, H.-T. Chang, Chem. Commun. 2014, 50, 9800.

[59] C. M. Ritchie, K. R. Johnsen, J. R. Kiser, Y. Antoku, R. M. Dickson, J. T. Petty, J. Phys. Chem. C Nanomater Interfaces 2007, 111, 175.

[60] C. I. Richards, S. Choi, J.-C. Hsiang, Y Antoku, T. Vosch, A. Bongiomo, Y. L. Tzeng, R. M. Dickson, J. Am. Chem. Soc. 2008, 130, 5038.

[61] Z. Cao, P. Wang, X. Qiu, C. Lau, L. Lu, Anal. Bioanal. Chem. 2014, 406, 1895.

[62] S. W. Yang, T. Vosch, Anal. Chem. 2011, 83, 6935.

[63] H. S. Yeh, J. Sharma, I.-M. Shih, D. M. Vu, J. S. Martinez, J. H. Werner, J. Am. Chem. Soc. 2012, 134, 11550.

[64] J. Yu, S. Choi, C. I. Richards, Y. Antoku, R. M. Dickson, Photochem. Photobiol. 2008, 84, 1435.
[65] D. S. Seferos, D. A. Giljohann, H. D. Hill, A. E. Prigodich, C. A. Mirkin, J. Am. Chem. Soc. 2007, 129, 15477.

[66] P. S. Randeria, W. E. Briley, A. B. Chinen, C. M. Guan, S. H. Petrosko, C. A. Mirkin, Cancer Treat. Res. 2015, 166, 1.

[67] R. Yang, J. Jin, Y. Chen, N. Shao, H. Kang, Z. Xiao, Z. Tang, Y. Wu, Z. Zhu, W. Tan, J. Am. Chem. Soc. 2008, 130, 8351.

[68] Y. Wang, A. Hu, J. Mater. Chem. C 2014, 2, 6921.

[69] R. Ye, Z. Peng, A. Metzger, J. Lin, J. A. Mann, K. Huang, C. Xiang, X. Fan, E. L. Samuel, L. B. Alemany, A. A. Martí, J. M. Tour, ACS Appl. Mater. Interfaces 2015, 7, 7041.

[70] S. Kim, S. W. Hwang, M.-K. Kim, D. Y. Shin, D. H. Shin, C. O. Kim, S. B. Yang, J. H. Park, E. Hwang, S. H. Choi, G. Ko, S. Sim, C. Sone, H. J. Choi, S. Bae, B. H. Hong, ACS Nano. 2012, 6, 8203.

[71] S. He, B. Song, D. Li, C. Zhu, W. Qi, Y. Wen, L. Wang, S. Song, H. Fang, C. Fan, Adv. Funct. Mater. 2010, 20, 453.

[72] C. H. Lu, H. H. Yang, C. L. Zhu, X. Chen, G. N. Chen, Angew. Chem. Int. Ed. Engl. 2009, 48, 4785.

[73] F. Liu, J. Y. Choi, T. S. Seo, Biosens. Bioelectron. 2010, 25, 2361.

[74] J. Lee, H. Kim, T. Sim, R. Song, Chem. Commun. 2013, 49, 6182.

[75] J. Zhou, Q. X. Wang, C. Y. Zhang, J. Am. Chem. Soc. 2013, 135, 2056.

[76] L. Zhang, R. Zhang, P. Cui, W. Cao, F. Gao, Chem. Commun. 2013, e49, 8102.

[77] J.-M. Liu, T.-L. Yang, F. Gao, L.-X. Hu, H.-X. He, Q.-Y. Liu, Z.-B. Liu, X.-M. Huang, G.-H. Zhu, Anal. Chim. Acta 2006, 561, 191.

[78] Y. He, H.-F. Wang, X.-P. Yan, Chemistry 2009, 15, 5436.

[79] F. van de Rijke, H. Zijlmans, S. Li, T. Vail, A. K. Raap, R. S. Niedbala, H. J. Tanke, Nat. Biotechnol. 2001, 19, 273.

[80] P. Corstjens, M. Zuiderwijk, A. Brink, S. Li, H. Feindt, R. S. Niedbala, H. Tanke, Clin. Chem. 2001, 47, 1885.

[81] L. Wang, Y. Li, Chem. Commun. 2006, 2557.

[82] R. Orbach, W. Guo, F. Wang, O. Lioubashevski, I. Willner, Langmuir 2013, 29, 13066.

[83] K. Du, S. H. Ko, G. M. Gallatin, H. P. Yoon, J. A. Liddle, A. J. Berglund, Chem. Commun. 2013, 49, 907.

[84] J. Ai, W. Guo, B. Li, T. Li, D. Li, E. Wang, Talanta 2012, 88, 450.

[85] R. Wang, C. Nuckolls, S. J. Wind, Angew. Chem. Int. Ed. Engl. 2012, 51, 11325.

[86] V. Simonetti, J. Y. Park, N. J. Panaro, L. J. Kricka, J. Nanoparticle, Res. 2008, 10, 365

[87] N. Li, D. Liu, H. Cui, Anal. Bioanal. Chem. 2014, 406, 5561.

[88] Z. Wang, J. Hu, Y. Jin, X. Yao, J. Li, Clin. Chem. 2006, 52, 1958.

[89] C. H. Liu, P. Z. Li, B. A. Du, X. R. Duan, Y. C. Wang, Anal. Chem. 2006, 78, 3738.

[90] S. Bi, H. Hong, S. Zhang, Chem. Commun. 2009, 5567.

[91] L. Chen, Int. J. Electrochem. Soc. 2011, 6, 5325.

[92] Z. Lin, W. Xue, H. Chen, J.-M. Lin, Chem. Commun. 2012, 48, 1051.

[93] Y. Wang, S. Wang, S. Ge, S. Wang, M. Yan, D. Zang, J. Yu, Anal. Methods 2013, 5, 1328.

[94] R. Duan, X. Zhou, D. Xing, Anal. Chem. 2010, 82, 3099.

[95] X. Wang, W. Yun, P. Dong, J. Zhou, P. He, Y. Fang, Langmuir 2008 24, 2200.

[96] X. Hu, R. Wang, Y. Ding, X. Zhang, W. Jin, Talanta 2010, 80, 1737.

[97] M. Yan, M. Zhang, S. Ge, J. Yu, M. Li, J. Huang, S. Liu, Analyst 2012, 137, 3314

[98] H. R. Zhang, J. J. Xu, H. Y. Chen, Anal. Chem. 2013, 85, 5321.

[99] M. Li, Y. Wang, Y. Zhang, S. Ge, M. Yan, Biosens. Bioelectron. 2014, 59, 307.

[100] F. Divsar, H. Ju, Chem. Commun. (Camb.) 2011, 47, 9879.

[101] H. Huang, J. Li, Y. Tan, J. Zhou, J.-J. Zhu, Analyst 2010, 135, 1773.

[102] J. Y. Park, L. J. Kricka, Lab Chip 2007, 7, 547. 
[103] S. I. Stolper, S. S. Mark, J. Y. Park, L. J. Kricka, Clin. Chem. 2007, 53, 1874.

[104] J. Y. Park, L. J. Kricka, Anal. Bioanal. Chem. 2014, 406, 5631.

[105] T. A. Taton, C. A. Mirkin, R. L. Letsinger, Science 2000, 289, 1757.

[106] A. V. Pinehiro, D. Han, W. M. Shih, H. Yan, Nat. Nanotechnol. 2011, 6, 763.
How to cite this article: Kricka, L. J., Fortina, P., and Park, J. Y. Nanostructured luminescently labeled nucleic acids. Luminescence. 2017;32:132-141. doi: 10.1002/bio.3170 